\title{
Assessing the history of the Greenland Ice Sheet through ocean drilling
}

\section{Corvallis, USA, 7-9 November 2011}

Anders Carlson ${ }^{1,2}$ and Joseph Stoner ${ }^{2}$

'Department of Geoscience, Center for Climatic Research, University of Wisconsin-Madison, USA; acarlson@coas.oregonstate.edu ${ }^{2}$ College of Earth, Ocean and Atmospheric Sciences, Oregon State University, Corvallis, USA

$T^{T}$ he primary goal of this workshop was to assess whether ocean drilling of the geological record can provide information on the sensitivity of the Greenland Ice Sheet (GIS) to climate warming. Discussion focused on potential marine archives, proxies of GIS behavior and climate, and methods for dating such records. The participants represented a range of disciplines, including climate and ice-sheet modelers, glaciologists, organic and inorganic geochemists, geophysicists, paleomagnetists, paleoceanographers, glacial geologists and sedimentologists, and paleobiologists. The group concluded that process-oriented topics could be addressed through ocean drilling and that the following questions were of significant importance: What controls the rate of ice mass change on Greenland and the respective roles of atmospheric and oceanic forcings? Is subsurface oceanic temperature important in predicting the behavior of the

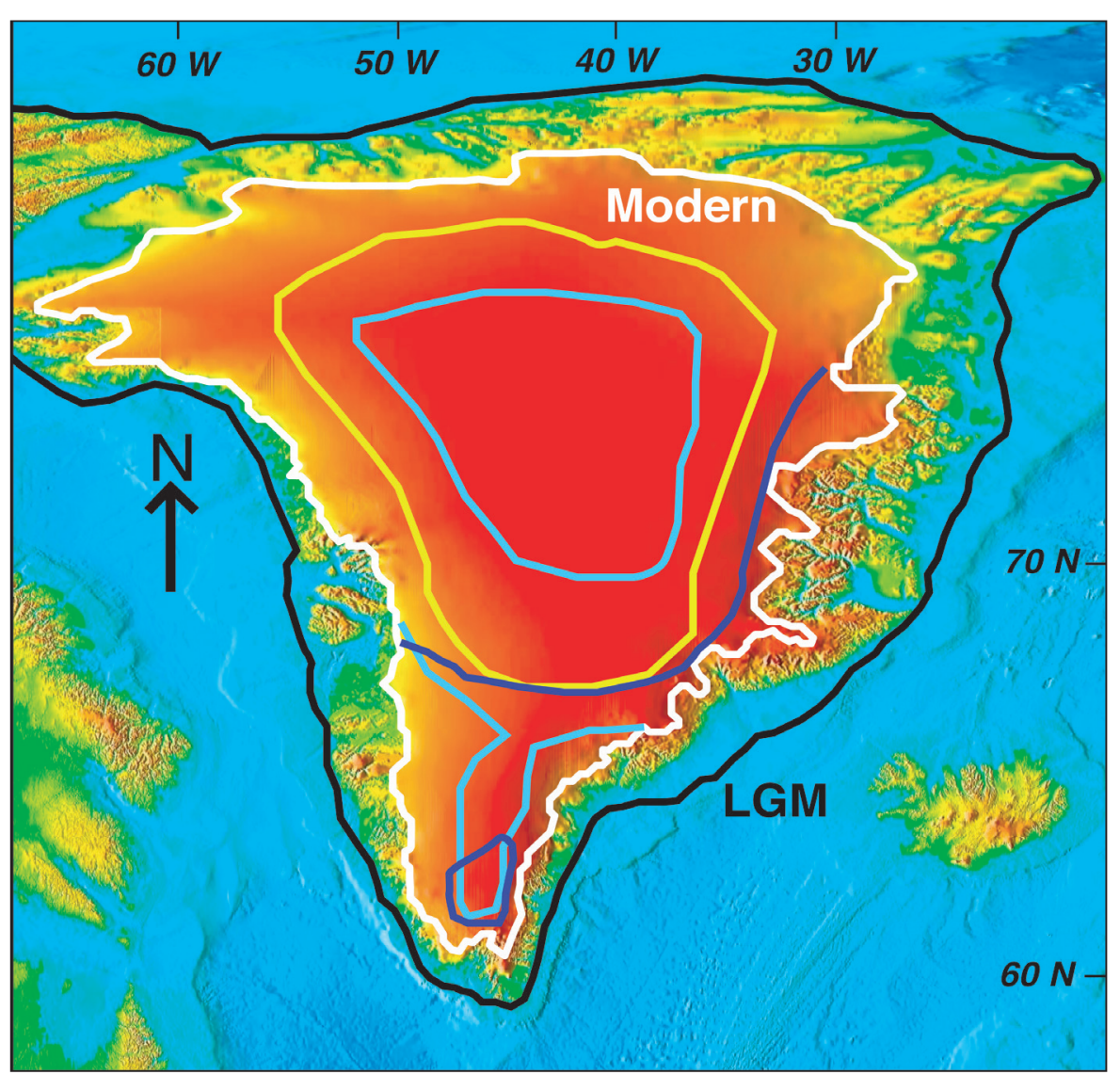

Figure 1: Last interglaciation ( 125 ka) modeled G/S extents using the same ice-sheet model but different climate forcing schemes. Light blue lines are two extents of Cuffey and Marshall (2000) with only a remnant ice dome in central Greenland or significant ice persisting in south Greenland. The dark blue line shows the maximum retreat modeled by Otto-Bliesner et al. (2006) with only a small ice dome persisting in south Greenland; a second simulation of their model had an extent similar to the minimum retreat of Cuffey and Marshall (2000). The yellow line denotes the minimum retreat predicted by Lhomme et al. (2005), with south Greenland completely deglaciated. The black line shows the estimated extent of the GIS at the last glacial maximum (LGM) on the continental shelf by Funder et al. (2011). This wide range in modeled last interglaciation GIS extents predicts a sea-level rise contribution of 2 to $5.5 \mathrm{~m}$, highlighting the need for geologic records of past GIS behavior. ice retreat inland of its current extent during interglacial Marine Isotope Stages 1, 5e, 7, 11, 19 and 31. The participants also noted that ice sheet-climate modelers should be involved at all steps of addressing these targeted time periods.

Different strategies and drilling platforms will be needed for tackling these questions and retrieving sediment cores covering the key time periods. Continental slope drilling cores could be used to address large-scale GIS changes, which can better inform ice-sheet models, but may be difficult to date. Smallscale instability related processes might be better addressed through localized investigation at the individual fjord outlet glacier scale on the continental shelf. Sediment drifts on the continental rise integrate these signals in well-dated records that will facilitate interpretation of the more proximal records. Ocean temperature and sea-ice records should also be constructed to test GIS sensitivity to oceanic changes. A reoccurring issue at the workshop was the need for detailed site surveying prior to drilling to identify the best sites for studying the climate targets and addressing the process-oriented questions. Extensive seismic surveying and bathymetric mapping will allow the collection of the best cores, and for the linkage of discontinuous continental shelf, fan and slope records to the continuous records obtained on the continental rise.

To continue the development of a "Greenland" community, the workshop conveners, Anders Carlson and Joseph Stoner, have set up a website for further discussion of ideas and advancement of drilling plans and proposals (www.geoscience.wisc.edu/degree). The conveners and steering committee will develop a working group called DEGREE (DEglaciated GREEnland) that will facilitate future workshops to advance research, and foster discussions of new records and model results of past GIS behavior and its climate forcings. The DEGREE strategy is to develop a community that will foster International Ocean Discovery Program (IODP) expedition proposals focusing on specific aspects of Greenland paleo-history.

\section{References}

Cuffy KM, Marshall SJ (2000) Nature 404: 591-594

Funder S et al. (2011) Developments in Quaternary Science 15: 699-713 Lhomme N, Clarke GKC, Marshall SJ (2005) Quaternary Science Reviews 24: $173-194$

Otto-Bliesner BL et al. (2006) Science 311: 1751-1753

PAGES news • Vol 20 • No 2 • December 2012 